This item was submitted to Loughborough's Research Repository by the author.

Items in Figshare are protected by copyright, with all rights reserved, unless otherwise indicated.

\title{
Plasma cytokine and exertional responses in relation to exercise intensity and volume of exercising muscle mass during arm-crank ergometry
}

\section{PLEASE CITE THE PUBLISHED VERSION}

http://dx.doi.org/10.1139/apnm-2014-0537

\section{PUBLISHER}

NRC Research Press (@ the authors)

VERSION

AM (Accepted Manuscript)

\section{PUBLISHER STATEMENT}

This work is made available according to the conditions of the Creative Commons Attribution-NonCommercialNoDerivatives 4.0 International (CC BY-NC-ND 4.0) licence. Full details of this licence are available at: https://creativecommons.org/licenses/by-nc-nd/4.0/

\section{LICENCE}

CC BY-NC-ND 4.0

\section{REPOSITORY RECORD}

Paulson, Thomas A.W., Victoria L. Goosey-Tolfrey, Christof A. Leicht, and Nicolette Bishop. 2019. "Plasma Cytokine and Exertional Responses in Relation to Exercise Intensity and Volume of Exercising Muscle Mass During Arm-crank Ergometry". figshare. https://hdl.handle.net/2134/17081. 
1 Plasma cytokine and exertional responses in relation to exercise intensity and volume of exercising muscle mass during arm-crank ergometry

3

4 Thomas A. Paulson ${ }^{1}$, Victoria L. Goosey-Tolfrey ${ }^{1}$, Christof A. Leicht ${ }^{1}$ \& Nicolette C.

5 Bishop ${ }^{1,2}$

6

$7 \quad{ }^{1}$ The Peter Harrison Centre for Disability Sport, School of Sport, Exercise and Health

8 Sciences, Loughborough University, Loughborough, LE11 3TU, ${ }^{2}$ National Institute for

9 Health Research (NIHR) Leicester-Loughborough Diet, Lifestyle and Physical Activity

10 Biomedical Research Unit, Loughborough University, LE11 3TU.

11 T.Paulson@,1boro.ac.uk

$12 \quad$ V.L.Tolfrey@,lboro.ac.uk

$13 \quad$ C.A.Leicht@,lboro.ac.uk

$14 \quad$ N.C.Bishop@,lboro.ac.uk

15

16

17 Corresponding Author:

18 Thomas A.W. Paulson PhD

19 The Peter Harrison Centre for Disability Sport

20 Loughborough University

21 Loughborough

22 LE11 3TU

23 Phone: $(+44) 1509226387$

24 Email: T.Paulson@lboro.ac.uk

25 


\section{Abstract}

2 This original study investigated the effect of submaximal exercise intensity and volume of contracting

3

4

5

6

7

8 muscle mass on plasma inflammation-mediating cytokine and perceived exertional responses to acute arm-crank ergometry (ACE). Twelve recreationally active but upper limb untrained males performed 30 min: 1) low intensity $\left(40 \% \dot{\mathrm{V}} \mathrm{O}_{2 \text { peak }}\right)$ ACE $\left.(\mathrm{LOW}) ; 2\right)$ moderate intensity $\left(60 \% \dot{\mathrm{V}} \mathrm{O}_{2 \text { peak }}\right)$ ACE (MOD); and 3) concurrent low intensity $\left(40 \% \dot{\mathrm{VO}}_{2 \text { peak }}\right)$ ACE plus lower limb cycle ergometry to match total power output in MOD (HYBRID). Plasma concentrations of IL-6, IL-10, IL-1ra, adrenaline and cortisol were determined at rest, immediately post-exercise, and $1 \mathrm{~h}$ and $2 \mathrm{~h}$ post-exercise. Heart rate (HR) and differentiated ratings of perceived exertion (RPE) were also recorded. Plasma IL-6 concentrations were elevated $(p<0.05)$ immediately post and $1 \mathrm{~h}$ post-exercise $(\sim 2.5$-fold $)$ in all trials and $2 \mathrm{~h}$ post-exercise in MOD ( 3 -fold). Plasma IL-1 ra concentrations were elevated $(p<0.05) 2 \mathrm{~h}$ postexercise in MOD only (2-fold). No plasma IL-10, cortisol and adrenaline responses were observed. HR and differentiated RPE were significantly higher during MOD than HYBRID and LOW. Peripheral RPE were significantly higher than central and overall RPE in each trial. Thirty minutes moderate intensity ACE initiated a plasma cytokine response associated with the protective effect of regular exercise against cardiovascular and metabolic disease risk. Further work is required to establish an optimal intensity and duration of upper limb exercise to maximise the anti-inflammatory potential whilst managing the risk of over-use injury.

\section{Key Words:}

Inflammation; Interleukin-6, Interleukin-1 Receptor Antagonist; Exercise prescription; Upper limb; Hybrid exercise; Rehabilitation 


\section{Introduction}

In populations with impaired lower limb function, participation in rehabilitation and regular physical exercise can be reliant on the musculature of the upper limb (Hicks et al. 2011; Treat-Jacobson et al. 2009; Woude et al. 2001). Exercise prescription must manage the risk of upper limb over-use whilst achieving exercise intensities sufficient to maintain or improve physical capacity and cardiovascular health (Woude et al. 2001). Arm crank ergometry (ACE) is considered safe and effective for many clinical populations including those with spinal cord injury (SCI) (Pelletier et al. 2014) and intermittent claudication (Tew et al. 2009; Treat-Jacobson et al. 2009). Well-structured, chronic upper limb exercise training employing ACE, manual wheelchair propulsion or hand cycling have been shown to positively influence physical capacity (Hicks et al. 2011) and cardiovascular disease risk profiles (de Groot et al. 2003; Saxton et al. 2008).

Contracting skeletal muscle releases the inflammation-mediating myokine interleukin-6 (IL-6) in a dose and time-dependent manner (Peake et al. 2005; Scott et al. 2011; Toft et al. 2011). The skeletal muscle-derived IL-6 response occurs secondary to a complex array of both intracellular (mechanical stimuli \& cytosolic calcium release) and extracellular (sympathetic nervous system (SNS)) signalling pathways (Welc \& Clanton 2013). Elevated plasma IL-6 concentrations are associated with postexercise elevations in circulating concentrations of the inflammation-suppressing cytokines IL-1ra, IL-10 and the soluble TNF receptor (Paulson et al. 2014; Peake et al. 2005; Scott et al. 2011). Observations from lower limb exercise models suggest a threshold intensity of $60-75 \%$ peak oxygen uptake $\left(\dot{\mathrm{VO}}_{2 \text { peak }}\right)$ is required to initiate significant elevations in plasma IL-1ra and IL-10 concentrations (Peake et al. 2005; Scott et al. 2011). The intensity and duration of upper limb exercise required to achieve an anti-inflammatory cytokine response, however, still remains unclear (Paulson et al. 2014; Paulson et al. 2013b).

Elevations in plasma IL-6 concentrations have been observed following 40 min strenuous, intermittent wheelchair propulsion ( $\sim 5$-fold) (Paulson et al. 2013b), $2 \mathrm{~h} \mathrm{ACE}$ at $60 \% \dot{\mathrm{VO}}_{2 \text { peak }}(\sim 6$-fold) (Umemoto et al. 2011) and just $20 \mathrm{~min} \mathrm{ACE}$ at $60 \% \dot{\mathrm{VO}}_{2 \text { peak }}$ ( 2-fold) (Kouda et al. 2012).). Previously, Helge et al. (2011) reported a greater IL-6 release from the upper versus lower limb despite a lower oxygen 
1 demand and glycogen utilisation during $60 \mathrm{~min}$ submaximal, whole body exercise. The smaller

2 muscle cross-sectional area of the upper versus lower limb may act to augment intracellular signalling

3 for IL-6 release per unit of contracting muscle when performing a given workload (Helge et al. 2011;

4 Steensberg et al. 2000). Low intensity exercise training is prescribed in some clinical environments to

5 limit peripheral fatigue and the risk of upper-limb over-use injury (de Groot et al. 2003; Van den Berg

6 et al. 2010). From a clinical perspective, it is of interest whether the upper limb may initiate an

7 inflammation-mediating cytokine response at lower absolute and/or relative intensities than observed

8 during lower limb exercise. Whether whole-body exercise, frequently adopted in populations with

9 SCI (Pelletier et al. 2014), orthopaedic stress (Chodzko-Zajko et al. 2009) and coronary artery disease

10 (Van Camp et al. 1994), provides a greater cytokine response compared with the same volume of

11 upper-limb exercise alone also warrants investigation.

12 The primary aim of this study was to compare the plasma cytokine and exertional responses to $30 \mathrm{~min}$ low $\left(40 \% \mathrm{VO}_{2 \text { peak }}\right)$ and moderate $\left(60 \% \mathrm{VO}_{2 \text { peak }}\right)$ intensity submaximal ACE. A secondary aim was to compare the same responses to low intensity $\left(40 \% \mathrm{VO}_{2 \text { peak }}\right) \mathrm{ACE}$ performed with concurrent leg cycle ergometry (LCE) to match the total power output (PO) performed during moderate intensity ACE alone. It was hypothesised that 30 min low and moderate intensity ACE would significantly elevate plasma IL-6 and anti-inflammatory cytokine concentrations, with a smaller response observed in the low intensity trial. Concurrent low intensity ACE and LCE was expected to increase load on the cardiovascular system (oxygen uptake, heart rate) compared to performing low intensity ACE alone, but have no influence on the plasma cytokine response.

Methods

\section{Participants \& Experimental design}

24 Twelve recreationally active males $\left(\right.$ age $=23 \pm 5 \mathrm{yr}$; body mass $=79.5 \pm 9.2 \mathrm{~kg} ;$ ACE $\dot{\mathrm{V}} \mathrm{O}_{2 \text { peak }}=$ $252.48 \pm 0.35 \mathrm{~L} \cdot \mathrm{min}^{-1} / 31.29 \pm 3.62 \mathrm{~mL} \cdot \mathrm{kg}^{-1} \cdot \mathrm{min}^{-1}$ ) were recruited from a local university population to participate in the study. Participants were required to be moderately physically active at least three 
1 times per week but not specifically upper-limb trained and asymptomatic of illness or pre-existing 2 injury. All participants provided written informed consent prior to commencing exercise. The study utilised a repeated measures design with all participants performing four exercise sessions. During the first visit, a submaximal incremental test and a graded exercise test to exhaustion to determine $\mathrm{V}_{2 \text { peak }}$ on an ACE were performed. For each participant a simple linear regression analysis was performed using the linear workload- $\dot{\mathrm{V}} \mathrm{O}_{2}$ relationship with data from the submaximal exercise test. The regression line created from the paired submaximal power output and $\dot{\mathrm{V}} \mathrm{O}_{2}$ data and the maximal $\dot{\mathrm{V}}_{2}$

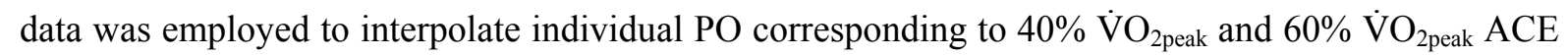
intensity. Subsequently, each participant performed three counter-balanced trials consisting of $30 \mathrm{~min}$ : 1) $40 \% \mathrm{VO}_{2 \text { peak }}$ ACE only (LOW); 2) $60 \% \mathrm{VO}_{2 \text { peak }} \mathrm{ACE}(\mathrm{MOD})$ and 3 ) Hybrid $40 \% \mathrm{VO}_{2 \text { peak }} \mathrm{ACE}$ plus LCE to match the total workload performed during MOD (HYB). Main trials were separated by at least $7 \mathrm{~d}$. All trials were completed within $24 \mathrm{~d}$. All procedures were approved by the University's Ethical Committee and performed in accordance with the Declaration of Helsinki.

\section{Preliminary measures}

On arrival at the laboratory, body mass was measured in the sitting position to the nearest $0.1 \mathrm{~kg}$ using double-beam scales (Marsden MPWS-300, Henley-on-Thames, UK). All exercise trials were performed using two electric-magnetically braked ergometers designed for upper and lower limb exercise (Lode, Lode B.V. Medical Technology, Groningen, the Netherlands). First, participants positioned themselves on the LCE and seat height was adjusted to allow lower-limb cycling with a slight flexion of the knee. Subsequently, arm crank ergometer height was adjusted to ensure the crank axis was level with the sternum at a distance allowing slight flexion of the elbow during cranking. Ergometer setup was standardized between trials. Heart rate (HR) was monitored continuously using radio telemetry (Polar PE 4000, Kempele, Finland). On-line respiratory gas analysis was carried out throughout each 4-min stage via a breath-by-breath system (Cortex metalyser 3B, Cortex, Leipzig, Germany). Before each test, gases were calibrated according to the manufacturer's recommendations using a 2-point calibration $\left(\mathrm{O}_{2}=17.0 \%, \mathrm{CO}_{2}=5.0 \%\right.$ against room air $)$ and volumes with a 3-L syringe at flow rates of $0.5-3.0 \mathrm{~L} \cdot \mathrm{s}^{-1}$. 
1 Following a standardized ACE warm-up of $20 \mathrm{~W}$ for $5 \mathrm{~min}$, participants performed an incremental

2 ACE only exercise test consisting of five 4-min constant load exercise stages at ascending PO,

3

4

5

6 intended to elicit physiological responses covering a range from $40 \%$ to $80 \% \dot{\mathrm{V}} \mathrm{O}_{2 \text { peak }}$. Initial POs were $20 \pm 5 \mathrm{~W}$ with subsequent PO increments of $20 \mathrm{~W}$. Crank rate was maintained between $70-80 \mathrm{rpm}$. The average respiratory data from the last 1-min of each stage was used to for the calculation of $\mathrm{VO}_{2}$. A small capillary blood sample was obtained from the earlobe at the start of the test and during a 1-min break between stages to determine blood lactate concentration (BLa $\left.{ }^{-}\right)$using a YSI 1500 SPORT Lactate Analyser (YSI Inc, Yellow Springs, OH). Differentiated ratings of perceived exertion (RPE, peripheral $\left(\mathrm{RPE}_{\mathrm{P}}\right)$, central $\left(\mathrm{RPE}_{\mathrm{C}}\right)$ and overall $\left.\left(\mathrm{RPE}_{\mathrm{O}}\right)\right)$ were recorded using the Borg 6-20 scale in the last $15 \mathrm{~s}$ of each 4-min stage while the participant was still exercising. Participants were given standardized instructions detailing the use of the Borg 6-20 scale and the associated verbal anchors at the beginning of each session as described elsewhere (Borg 1998).

After a 15 -min rest period, a graded exercise test to exhaustion was performed to determine $\dot{\mathrm{V}} \mathrm{O}_{2 \text { peak }}$. The test involved increments of $10 \mathrm{~W}$ every minute from an initial PO of $40 \pm 9 \mathrm{~W}$ at a freely chosen crank rate above $60 \mathrm{rpm}$ until volitional exhaustion. Expired air and HR were measured continuously throughout the test and the differentiated RPE at exhaustion was recorded as previously described. Breath-by-breath data allowed the highest 30 s rolling average $\dot{\mathrm{VO}}_{2}$ value recorded during the exercise test to be taken as the $\dot{\mathrm{V}}_{2 \text { peak. }}$. In accordance with guidelines for upper limb exercise testing (GooseyTolfrey 2008), criteria for a $\dot{\mathrm{VO}}_{2 \text { peak }}$ were the presence of 2 of the following 3 conditions: 1) a plateau in $\dot{\mathrm{VO}}\left(<2 \mathrm{ml} \cdot \mathrm{kg} \cdot \mathrm{min}^{-1}\right)$ over the last two incremental stages of the test; 2$)$ peak RER value $>1.10$; and 3) a peak HR $>95 \%$ age-predicted maximum ( $200 \mathrm{bpm}^{-1}$ minus chronological age).

\section{Main experimental trials}

$40 \% \dot{V} O_{2 p e a k} A C E(L O W)$ and $60 \% \dot{V} O_{2 p e a k} A C E(M O D)$

A standardized 5-min upper limb warm-up at $20 \mathrm{~W}$ was performed prior to all main trials. The armcrank ergometer was then set at the imposed PO corresponding to $40 \% \dot{\mathrm{VO}}_{2 \text { peak }}$ and $60 \% \dot{\mathrm{V}} \mathrm{O}_{2 \text { peak }}$ and participants were asked to maintain a cadence of $70-80 \mathrm{rpm}$ for $30 \mathrm{~min}$. $\mathrm{HR}$ and respiratory data $\left(\mathrm{V}_{2}\right.$ 
1 and exchange ratio (RER)) were measured constantly during each bout and averaged over a $60 \mathrm{~s}$

2 period every $10 \mathrm{~min}$. Data at $10 \mathrm{~min}$ intervals was then averaged to provide an average for the $30 \mathrm{~min}$

5 Participants performed a 5-min LCE warm-up at an intensity of $20 \mathrm{~W}$ concurrent with the trial. Differentiated RPE and $\mathrm{BLa}^{-}$were recorded at the end of each trial.

$40 \% \dot{V} O_{2 p e a k} A C E$ and leg cycle ergometry to match total PO during MOD (HYB) standardized ACE warm-up. The difference in PO between the LOW and MOD trials was calculated for each participant and provided the imposed intensity of LCE performed in addition to ACE. Therefore, the ACE load was identical for the LOW and HYB trials. In turn, total PO was identical for the MOD and HYB trials. Participants were asked to maintain a cadence of 70-80 rpm for ACE and 80-90 rpm for LCE for the 30 min bout. HR, respiratory data, differentiated RPE and $\mathrm{BLa}^{-}$were determined as previously described. Previously, a 15-min familiarisation period to the hybrid exercise modality was provided for each participant during the preliminary visit at a standardized $30 \mathrm{~W}$ and 20 W for ACE and LCE load respectively.

\section{Blood analyses}

A $7.5 \mathrm{ml}$ blood sample was collected before, immediately after exercise, $1 \mathrm{~h}$ post-exercise and $2 \mathrm{~h}$ post exercise from an antecubital vein into a $\mathrm{K}_{3}$ EDTA vacutainer. Blood samples were refrigerated until the final sample from each participant was collected and then spun down together in a refrigerated $\left(4^{\circ} \mathrm{C}\right)$ centrifuge at $1500 \mathrm{~g}$ for $10 \mathrm{~min}$. The separated plasma was then immediately stored at $-80^{\circ} \mathrm{C}$. Plasma concentrations of IL-6, IL-10, IL-1ra, cortisol and epinephrine were determined using quantitative sandwich-type enzyme-linked immunosorbant assay (ELISA) kits (IL-6, IL-10, , IL-1ra: R\&D systems, Abingdon, UK; cortisol: DRG instruments, Marburg, Germany; epinephrine: IBL international, Hamburg, Germany), according to the manufacturers' instructions. All samples were analysed in duplicate. The within assay co-efficient of variation for the analyses performed were as follows: adrenaline: 3.0\%; cortisol: 2.5\%; IL-6: 5.4\%; IL-10: 5.0\% and IL-1ra: $6.2 \%$. 
2 All data were analysed using the statistical package IBM SPSS for windows version 20 (SPSS inc,

3 Chicago, IL). Normal distribution of the outcome variables was confirmed for all data using a

4 Shapiro-Wilk test. Plasma cytokine and hormone data were analysed in a two factor (trial $\mathrm{x}$ time of measurement) mixed measures ANOVA. Where significant F-ratios were shown, separate one-way repeated measures ANOVA with Tukey post-hoc tests were employed to determine changes across time within each trial. Separate paired students t-tests were employed to determine differences between trials at each time point. A Bonferroni adjustment was performed on the unadjusted alpha value when performing multiple comparisons. For comparisons where the assumption of sphericity was violated, a Greenhouse-Geisser correction was applied. $\mathrm{PO}, \dot{\mathrm{VO}}_{2}, \mathrm{HR}$, RER and $\mathrm{BLa}^{-}$data were analysed by paired students t-tests. All differentiated RPE data were analysed by non-parametric Friedman and Wilcoxon signed-rank tests. Data are presented as mean \pm standard deviation except ordinal RPE data which is presented as median (quartile ranges). Significance was set a priori at $p \leq 0.05$.

\section{Results}

Plasma IL-6 concentrations showed a significant main effect for time $(p=0.02)$ and trial $\mathrm{x}$ time interaction $(p=0.04)$. Post-hoc analysis showed plasma IL-6 concentrations were significantly $(p<0.05)$ elevated immediately post exercise ( $\sim 2$-fold $)$ and at post $1 \mathrm{~h}$ post exercise $(\sim 2.5$-fold $)$ in each trial. At $2 \mathrm{~h}$ post exercise, plasma IL-6 concentrations following MOD were significantly elevated above rest (3-fold) $(p=0.03)$ and significantly higher than LOW and HYB $(p<0.05)$ (Figure 1). A significant main effect for time $(p=0.01)$ and trial $\mathrm{x}$ time interaction $(p=0.02)$ were also present for plasma IL-1ra concentrations. Plasma IL-1ra was unaffected by exercise in LOW and HYB. In contrast, a significant elevation was seen at $2 \mathrm{~h}$ post exercise in MOD (2-fold) compared to pre exercise $(p=0.005)$ (Figure 1). At $2 \mathrm{~h}$ post exercise, plasma IL-1ra concentrations in MOD were significantly higher than LOW ( $p=0.03$ ) but not HYB. No significant effects were observed for plasma IL-10 concentrations (Figure $1)$.

\section{[Insert Figure 1]}


2 A significant effect for time $(p=0.01)$ but non-significant trial $\mathrm{x}$ time interaction were present for 3 plasma cortisol. In all trials, plasma cortisol concentrations were significantly lower at $1 \mathrm{~h}$ and $2 \mathrm{~h}$ post exercise compared to pre exercise $(p<0.01)$ (Figure 2). No significant main effects were observed for plasma adrenaline concentrations (Figure 2).

\section{[Insert Figure 2]}

A comparison of the physiological responses across the three main trials is provided in Table 1. PO, $\dot{\mathrm{V}} \mathrm{O}_{2}, \% \dot{\mathrm{V}} \mathrm{O}_{2 \text { peak }}$, HR and \%HRpeak were significantly higher during MOD and HYB than LOW. In addition, $\mathrm{HR}, \% \mathrm{HRpeak}$ and $\mathrm{BLa}^{-}$were significantly higher in MOD than HYB. No difference in RER was found between any trials. The differentiated RPE responses for all trials are shown in Table 2. All differentiated RPE were significantly higher in MOD than HYB, with HYB higher than LOW. $\mathrm{RPE}_{\mathrm{P}}$ was significantly $(p<0.05)$ higher than $\mathrm{RPE}_{\mathrm{C}}$ and $\mathrm{RPE} \mathrm{E}_{\mathrm{O}}$ within each trial.

\section{[Insert Table 1]}

\section{[Insert Table 2]}

\section{Discussion}

The present study investigated whether the contracting upper limb may initiate a inflammationmediating plasma cytokine response at lower absolute and relative intensities than previously observed during lower limb exercise (Peake et al. 2005; Scott et al. 2011). In support of our hypothesis, a significant increase in plasma IL-6 (2-fold) was seen immediately post and $1 \mathrm{~h}$ post low $\left(40 \% \dot{\mathrm{V}}_{2 \text { peak }}\right)$ and moderate $\left(60 \% \dot{\mathrm{VO}}_{2 \text { peak }}\right)$ intensity ACE. To the authors' knowledge, this is the first study to report 30 min moderate intensity ACE is sufficient to initiate a significant plasma IL-6 (3fold) and IL-1 ra response (2-fold) $2 \mathrm{~h}$ post exercise. The inflammation mediating cytokine response in both trials was independent of SNS or hypothalamic-pituitary-adrenal (HPA) axis activation. This was 
1 evidenced by an absence of a plasma adrenaline response in any trial and no difference between trials

2 with respect to the plasma cortisol response. As expected, the addition of concurrent lower limb cycling to low intensity ACE did not augment the plasma IL-6 response compared to low intensity ACE alone.

The intensity and duration of exercise are known modulators of the intracellular and extracellular signalling pathways regulating contraction-induced elevations in plasma inflammation-mediating cytokine concentrations (Gleeson et al. 2011; Welc and Clanton et al. 2013). In concert with reduced visceral adiposity, this transient anti-inflammatory environment may provide a protective effect of regular exercise against the development and progression of inflammation-driven, metabolic and cardiovascular diseases (Gleeson et al. 2011). Previous findings from our research group (Paulson et al. 2013b) and others (Peake et al. 2005; Scott et al. 2011) suggest a large contribution of extracellular, SNS mediated, signalling pathways to the plasma IL-6 response observed following vigorous intensity exercise $\left(4-8 \mathrm{pg} \cdot \mathrm{ml}^{-1}\right)\left(75-80 \% \dot{\mathrm{VO}}_{2 \text { peak }}\right.$ and higher). Elsewhere, more modest elevations in plasma IL-6 $\left(1.5-4 \mathrm{pg} \cdot \mathrm{ml}^{-1}\right)$ and IL-1ra $\left(150-200 \mathrm{pg} \cdot \mathrm{ml}^{-1}\right)$ concentrations have been observed following 60 min treadmill running at $60-65 \% \dot{\mathrm{V}}_{2 \text { peak }}($ Scott et al. 2011). The present findings suggest $30 \mathrm{~min}$ ACE at $60 \% \dot{\mathrm{VO}}_{2 \text { peak }}$ is sufficient to initiate an IL-6 and IL-1ra response despite the lower observed absolute PO and oxygen uptake compared to lower limb exercise.

As a naturally occurring antagonist to the pro-inflammatory cytokines IL-1 $\alpha$ and IL-1 $\beta$, plasma IL-1ra is an important modulator of systemic inflammation and innate immune responses (Dinarello 2011). To date, the absolute concentration of IL-6 required for the initiation of an IL-1ra response in vivo following exercise remains unknown. However, the findings from the current study suggest an elevation in plasma IL-6 concentrations of around $1 \mathrm{pg} \cdot \mathrm{ml}^{-1}$ may be sufficient to initiate an IL-1ra response. IL-10 is another potent modulator of both adaptive and innate immunity (Maynard \& Weaver 2008). In contrast to IL-1ra, it appears more vigorous exercise intensities than investigated in the present study are required to elevate plasma IL-10 concentrations (Peake et al. 2005) as catecholamines are a known modulator of IL-10 secretion in vitro (Platzer et al. 2000). Therefore, 
1 elevations in plasma IL-10 following exercise may be more closely related to SNS activation rather

2 than the acute IL-6 response.

3 The morphological characteristics of the upper limb, including small cross-sectional and diffusional muscle surface areas, limit attainable power outputs and provide a peripheral limitation to

5 performance in untrained individuals, respectively (Calbet et al. 2005; Kang et al. 1997). Previously,

6 plasma IL-6 concentrations remained unchanged following 40 min low intensity leg cycle ergometry

7 at an absolute intensity ( $\sim 60 \mathrm{~W})$ equivalent to moderate intensity ACE performed in the present study

8 (Mendham et al. 2011). The plasma IL-6 response observed following both LOW and MOD support

9 the role of intra-cellular signalling pathways, including mechanical stress and cytosolic calcium concentrations (Welc and Clanton 2013), in determining the magnitude of response to submaximal exercise. In addition, a significant IL-6 response was observed $1 \mathrm{hr}$ post low intensity ACE, with no augmentation in response with the addition of an equivalent load of voluntary lower limb cycle ergometry.

Low intensity exercise training is commonly prescribed during the acute stages of rehabilitation to limit peripheral fatigue and the risk of upper-limb over-use injury whilst enhancing physical capacity (de Groot et al. 2003; Van den Berg et al. 2010). Exercise prescription guidelines for the general populations suggest at least 20 min moderate to vigorous activity on at least 3 days per week (Garber et al. 2011). A limitation of present findings is that the absolute intensity of ACE performed in the moderate trial may be greater than can be achieved by some clinical populations. Further work is required to investigate the optimal dose of upper limb exercise to achieve a transient elevation in plasma anti-inflammatory cytokine concentrations. Whether shorter, more intense bouts of interval based training as described in lower limb literature (Gibala et al. 2012) are practical or efficacious in untrained or clinical population's warrants attention. However, it must be acknowledged that the transient anti-inflammatory cytokine response to acute exercise is only one proposed mechanism for the protective effect of regular physical exercise against the risk of chronic disease (Gleeson et al. 2011). Despite the absence of an augmented plasma cytokine response, the present findings suggest concurrent lower and upper limb may provide an alternative for maximising cardiovascular load and 
1 energy expenditure versus traditional upper limb modalities. The addition of voluntary (Hagerman et

2 al. 1988) or involuntary, electrically stimulated (Paulson et al. 2014) lower limb contractions to

3 concurrent upper limb exercise can increase energy expenditure above modalities employing either

4 muscle group alone. Whole-body, weight supported exercise modalities employing rowing or hybrid

5 cycle-ergometry are recommended in individuals with a low tolerance to orthopaedic stress

6 (Chodzko-Zajko et al. 2009) and coronary artery disease (Van Camp et al. 1994).

\section{Conclusion}

8 This study aimed to further scientific knowledge supporting the prescription of regular physical

9 activity and exercise involving the upper limb. The major finding was that 30 min moderate but not

10 low intensity ACE resulted in an IL-6 response associated with subsequent elevation in plasma

11 concentrations of the anti-inflammatory cytokine IL-1ra. This response occurred independent of SNS activation and at a lower absolute power output than previously observed in lower limb exercise

13 literature. No additional plasma IL-6 response but a greater oxygen uptake was observed following

14 low intensity ACE with the addition of a workload of $\sim 35 \mathrm{~W}$ of lower-limb cycling. Moderate intensity ACE with higher levels of peripheral perceived exertion therefore appears necessary to initiate the transient anti-inflammatory environment associated with the cardioprotective effect of exercise. . Further longitudinal research is required to maximise the anti-inflammatory potential of regular exercise employing the upper limb via manipulations in the intensity and/or duration prescribed. 


\section{Acknowledgements}

2 The authors would like to thank Dr John Lenton, Miss Rachel Squires and Mr Luke Oates for their 3 contributions to data collection and the participants who volunteered to take part. A grant from the

4 Coca-Cola Foundation was received for consumable costs during this research along with additional

5 support provided by the corresponding institution. Dr N.C. Bishop is supported by the National

6 Institute for Health Research (NIHR) Diet, Lifestyle \& Physical Activity Biomedical Research Unit

7 based at University Hospitals of Leicester and Loughborough University. The views expressed are

8 those of the authors and not necessarily those of the NHS, the NIHR or the Department of Health. The

9 authors are not aware of any conflict of interest. 
2 Al-Rahamneh, H.Q., Faulkner, J.A., Byrne, C. \& Eston, R.G. 2010. Relationship between perceived 3 exertion and physiologic markers during arm exercise with able-bodied participants and participants 4 with poliomyelitis. Arch. Phys. Med. Rehab. 91(2), 273-277.

5 Borg, G. 1998. Borg's perceived exertion and pain scales. Human Kinetics Publishers. Champaign, IL.

6 Calbet, J.A.L., Holmberg, H.C., Rosdahl, H., van Hall, G., Jensen-Urstad, M. \& Saltin, B. 2005. Why 7 do the arms extract less oxygen than legs during exercise? Am. J. Physiol. 289, 1448-1458.

8 Chodzko-Zajko, W.J., Proctor, D.N., Singh, M.A., Minson, C.T., Nigg, C.R., Salem, G.J. \& Skinner, 9 J.S. 2009. American College of Sports Medicine position stand, exercise and physical activity for older adults. Med. Sci. Sports. Exer. 41(7), 1510-1530.

de Groot, P.C., Hjeltnes, N., Heijboer, A., Stal, W. \& Birkeland, K. 2003. Effect of training intensity on physical capacity, lipid profile and insulin sensitivity in early rehabilitation of spinal cord injured individuals. Spinal Cord. 41(12), 673-679.

Dinarello, C.A. 2011. Interleukin-1 in the pathogenesis and treatment of inflammatory diseases. Blood. $117,3720-3732$.

Garber, C.E., Blissmer, B., Deschenes, M.R., Franklin, B., Lamonte, M.J., Lee, I., Nieman, D.C. \& Swain, D.P. 2011. American College of Sports Medicine position stand. Quantity and quality of exercise for developing and maintaining cardiorespiratory, musculoskeletal, and neuromotor fitness in apparently healthy adults: guidance for prescribing exercise. Med. Sci. Sports. Exer. 43(7), 1334-1359.

Goosey-Tolfrey V.L. (2008). The disabled Athlete. In: Winter E, Jones A, Davison, R, Bromley P, Mercer T, (eds) BASES sport and exercise physiology testing guidelines, Vol. 1: sport testing. Routledge, Oxford, 359-367

Gibala, M.J., Little, J.P., MacDonald, M.J. \& Hawley, J.A. (2012). Physiological adaptations to lowvolume, high intensity interval training in health and disease. J. Physiol. 590(5), 1077-1084. guidelines for adults with spinal cord injury. Spinal Cord. 49(11), 1088-1096. 
1 Gleeson, M., Bishop, N.C., Stensel, D.J., Lindley, M.R., Mastana, S.S. \& Nimmo, M.A. 2011. The

2 anti-inflammatory effects of exercise: mechanisms and implications for the prevention and treatment

3 of disease. Nat. Rev. Immunol. 11(9), 607-615.

4 Hagerman, F.C., Lawrence, R.A. \& Mansfield, M.C. 1988. A comparison of energy expenditure 5 during rowing and cycle ergometry. Med. Sci. Sports. Exer. 20(5), 479-488.

6 Helge, J.W., Klein, D.K., Andersen, T.M., van Hall, G., Calbet, J., Boushel, R. \& Saltin, B. 2011.

7 Interleukin-6 release is higher across arm than leg muscles during whole-body exercise. Exp. Physiol,

8 96(6), 590-598.

9 Hicks, A.L., Martin Ginis, M.A., Pelletier, C.A., Ditor, D.S., Foulon, B. \& Wolfe, D.L. 2011. The effects of exercise training on physical capacity, strength, body composition and functional performance among adults with a spinal cord injury: a systematic review. Spinal Cord. 49, 1103-1127.

Kang, J., Robertson, R.J., Goss, F.L., Dasilva, S.G., Suminiski, R.R., Utter, A.C., Zoeller, R.F. \& Metz, K.F. 1997. Metabolic efficiency during arm and leg exercise at the same relative intensities. Med. Sci. Sports. Exer. 29(3), 377-382.

Kouda, K., Furusawa, K., Sugiyama, H., Sumiya, T., Ito, T., Tajima, F. \& Shimizu, K. 2012. Does 20min arm crank ergometer exercise increase plasma interleukin-6 in individuals with cervical spinal cord injury? Eur. J. Appl. Physiol. 112(2), 597-604.

Maynard, C.L. \& Weaver, C.T. 2008. Diversity in the contribution of interleukin-10 to T-cellmediated immune regulation. Immunol. Rev. 226(1), 219-233.

Mendham, A.E., Donges, C.E., Liberts, E.A. \& Duffield, R. 2011. Effects of mode and intensity on the acute exercise-induced IL-6 and CRP responses in a sedentary, overweight population. Eur. J. Appl. Physiol. 111(6), 1035-1045. cytokine response to acute hand cycling exercise with/without functional electrical stimulationevoked lower-limb cycling. J. Rehab. Res. Dev. 51(4), 645-654. exertion and self-regulated wheelchair exercise. Arch. Phys. Med. Rehab. 94: 2260-2279. 
1 Paulson, T.A.W, Goosey-Tolfrey, V.L., Lenton, J.P., Leicht, C.A. \& Bishop, N.C. 2013b. Spinal cord 2 injury level and the circulating cytokine response to strenuous exercise. Med. Sci. Sports. Exer. 3 45(9):1649-1655.

4 Peake, J.M., Suzuki, K., Hordern, M., Wilson, G., Nosaka, K. \& Coombes, J.S. 2005. Plasma 5 cytokine changes in relation to exercise intensity and muscle damage. Eur. J. Appl. Physiol. 95(5-6), $6 \quad 514-521$.

7 Pelletier, C.A., Ditor, D.S. Ditor, Latimer-Cheung, A.E., Warburton, D.E. \& Hicks, A.L. 2014. 8 Exercise equipment preferences among adults with spinal cord injury. Spinal Cord. 52 (874-879).

9 Platzer, C., Döcke, W., Volk, H. \& Prösch, S. 2000. Catecholamines trigger IL-10 release in acute 10 systemic stress reaction by direct stimulation of its promoter/enhancer activity in monocytic cells. J. 11 Neuroimmunol. 105(1), 31-38. Saxton, J.M., Zwierska, I., Hopkinson, K., Espigares, E., Choksy, S., Nawaz, S., et al. 2008. Effect of upper and lower limb training on circulating soluble adhesion molecules, $h s$-CRP and stress proteins in patients with intermittent claudication. Eur. J. Vas. Endo. Surgery. 35, 607-613.

Scott, J., Sale, C., Greeves, J.P., Casey, A., Dutton, J. \& Fraser, W.D. 2011. Effect of exercise intensity on the cytokine response to an acute bout of running. Med. Sci. Sports. Exer. 43(12), 22972306.

Steensberg, A., Van Hall, G., Osada, T., Sacchetti, M., Saltin, B. \& Pedersen, B.K. 2000. Production of interleukin-6 in contracting human skeletal muscles can account for the exercise-induced increase in plasma interleukin-6. J. Physiol. 529(1), 237-242.

Toft, A.D., Falahati, A. \& Steensberg, A. 2011. Source and kinetics of interleukin-6 in humans during exercise demonstrated by a minimally invasive model. Eur. J. Appl. Physiol. 111(7), 13511359.

Tew, G. Nawaz, S., Zwierska, I, Saxton, J.M. 2009. Limb-specific and cross-transfer effects of arm crank exercise training in patients with symptomatic peripheral arterial disease. Clinical Science. 117 , 405-413.

Treat-Jacobson, D., Bronas, U.G., Leon, A.S. 2009. Efficacy of arm-ergometry versus treadmill exercise to improve walking distance in patients with claudication. Vas. Med. 14(3), 203-213. 
1 Umemoto, Y., Furusawa, K., Kouda, K., Sasaki, Y., Kanno, N., Kojima, D. \& Tajima, F. 2011.

2 Plasma IL-6 levels during arm exercise in persons with spinal cord injury. Spinal Cord. 49, 1182-1187.

3 Van Camp, S.P., Cantwell, J.D., Fletcher, G.F., Smith, K. \& Thomapson, P.D. 1994. American

4 College of Sports Medicine position stand, exercise for patients with coronary artery disease. Med.

5 Sci. Sports. Exer. 26(3), i-v.

6 Van den Berg, R., de Groot, S., Swart, K.M.A. \& Woude van der, L.H.V. 2010. Physical capacity

7 after 7 weeks of low-intensity wheelchair training. Disabil. \& Rehab. 32(21), 1713-1721.

8 Welc, S.S. \& Clanton, T.L. 2013. The regulation of IL-6 implicates skeletal muscle as an integrative 9 stress sensor and endocrine organ. Exp. Physiol. 98(2), 359-371.

10 Woude van der, L.H.V., Veeger, H.E.J., Dallmeijer, A.J., Janssen, T.W.J. \& Rozendaal L.A. 2001.

11 Biomechanics and physiology in active manual wheelchair propulsion. Med. Eng. Phys. 23, 712-73. 
1 Table 1 Physiological responses to 30 min low intensity ACE (LOW), moderate intensity ACE

2 (MOD) and concurrent upper and lower limb ergometry (HYBRID)

\begin{tabular}{|c|c|c|c|}
\hline Parameter & LOW & MOD & HYBRID \\
\hline PO $(W)$ & $38 \pm 11^{\mathrm{a}}$ & $70 \pm 16$ & $70 \pm 16$ \\
\hline$\dot{\mathbf{V}} \mathbf{O}_{2}\left(\mathrm{~L} \cdot \mathrm{min}^{-1}\right)$ & $0.96 \pm 0.16^{\mathrm{a}}$ & $1.50 \pm 0.26$ & $1.56 \pm 0.31$ \\
\hline$\% \dot{\mathbf{V}} \mathbf{O}_{2 \text { peak }}(\mathrm{ACE})$ & $40 \pm 3^{\mathrm{a}}$ & $62 \pm 7$ & $64 \pm 6$ \\
\hline HR $\left(b \cdot \min ^{-1}\right)$ & $109 \pm 14^{\mathrm{a}}$ & $139 \pm 10$ & $127 \pm 16^{\mathrm{b}}$ \\
\hline$\% \mathrm{HR}_{\text {peak }}$ & $60 \pm 8^{a}$ & $77 \pm 8$ & $70 \pm 9^{b}$ \\
\hline RER & $0.96 \pm 0.05$ & $1.01 \pm 0.06$ & $0.94 \pm 0.05$ \\
\hline $\mathrm{BLa}^{-}\left(\mathrm{mmol}^{-\mathrm{I}^{-1}}\right)$ & $1.66 \pm 0.83^{b}$ & $3.05 \pm 1.37$ & $1.59 \pm 0.54^{b}$ \\
\hline
\end{tabular}

3

4

5

6

7

8

9

10

11

12

13

14

15

16

17

列

Note. $a=$ significantly different from MOD and HYB; $b=$ significantly different from MOD. Data are mean \pm standard deviation.

$\mathrm{PO}=$ power output $; \dot{\mathrm{V}} \mathrm{O}_{2}=$ oxygen uptake; $\% \dot{\mathrm{V}} \mathrm{O}_{2 \text { peak }}=$ percentage of peak oxygen uptake; $\mathrm{HR}=$ heart rate; $\mathrm{RER}=$ respiratory exchange ratio $; \mathrm{BLa}^{-}=$blood lactate concentration.

\section{8}


1 Table 2 Differentiated RPE responses to 30 min low intensity ACE (LOW), moderate intensity ACE

2 (MOD) and concurrent upper and lower limb ergometry (HYBRID)

3

4

5

6

7

8

9 Note. $\mathrm{a}=\mathrm{RPE} \mathrm{E}_{\mathrm{P}}$ significantly different from $\mathrm{RPE}_{\mathrm{O}}$ and $\mathrm{RPE} \mathrm{E}_{\mathrm{C}}$ within trial; $\mathrm{b}=\mathrm{RPE}_{\mathrm{O}}$ significantly 10

\begin{tabular}{|c|c|c|c|}
\hline & RPE $_{\mathrm{P}}$ & $\mathrm{RPE}_{\mathrm{C}}$ & $\mathrm{RPE}_{\mathrm{O}}$ \\
\hline LOW $^{\mathbf{c}}$ & $11(9,13)^{\mathrm{a}}$ & $9(8,10)$ & $11(8,11)$ \\
HYBRID $^{\mathbf{d}}$ & $14(12,16)^{\mathrm{a}}$ & $13(11,13)$ & $13(12,15)^{\mathrm{b}}$ \\
& $14(1,15)^{\mathrm{a}}$ & $11(9,14)$ & $13(10,15)$ \\
\hline
\end{tabular}

(

different from $\mathrm{RPE}_{\mathrm{C}}$ within trial; $\mathrm{c}=$ MOD significantly different from LOW and HYB for all 1 differentiated RPE; $\mathrm{d}=$ HYB significantly different from LOW within differentiated RPE. $(p<0.05)$.

$\mathrm{PO}=$ power output; $\dot{\mathrm{V}} \mathrm{O}_{2}=$ oxygen uptake; $\% \dot{\mathrm{V}}_{2}$ peak $=$ percentage of peak oxygen uptake; $\mathrm{HR}=$ heart 3 rate; $\mathrm{RER}=$ respiratory exchange ratio; $\mathrm{BLa}^{-}=$blood lactate concentration; $\mathrm{RPE}_{\mathrm{P}}=$ peripheral $\mathrm{RPE}$; $4 \quad \mathrm{RPE}_{\mathrm{C}}=$ central RPE; $\mathrm{RPE}_{\mathrm{O}}=$ overall RPE. 
1 Figure 1 Plasma cytokine responses to 30 min low intensity ACE (LOW), moderate intensity ACE

2 (MOD) and concurrent upper and lower limb ergometry (HYBRID)

3 Note. Time effects: $\mathrm{a}=$ All groups significantly higher than pre-exercise; $\mathrm{b}=$ MOD significantly

4 higher than pre-exercise. Group effects: $c=$ MOD significantly higher than LOW and HYBRID; d = 5 MOD significantly higher than LOW, $(p<0.05)$

6

7

8 Figure 2 Plasma adrenaline and cortisol responses to 30 min low intensity ACE (LOW), moderate

9 intensity ACE (MOD) and concurrent upper and lower limb ergometry (HYBRID)

10 Note. Time effects: e = all groups significantly lower than pre-exercise $(p<0.05)$

11

12 
1

3

4

5

6

7

8

9

10

11

12

13

14

15

16

17

18

19

20

21

22

23

24

Figure 1
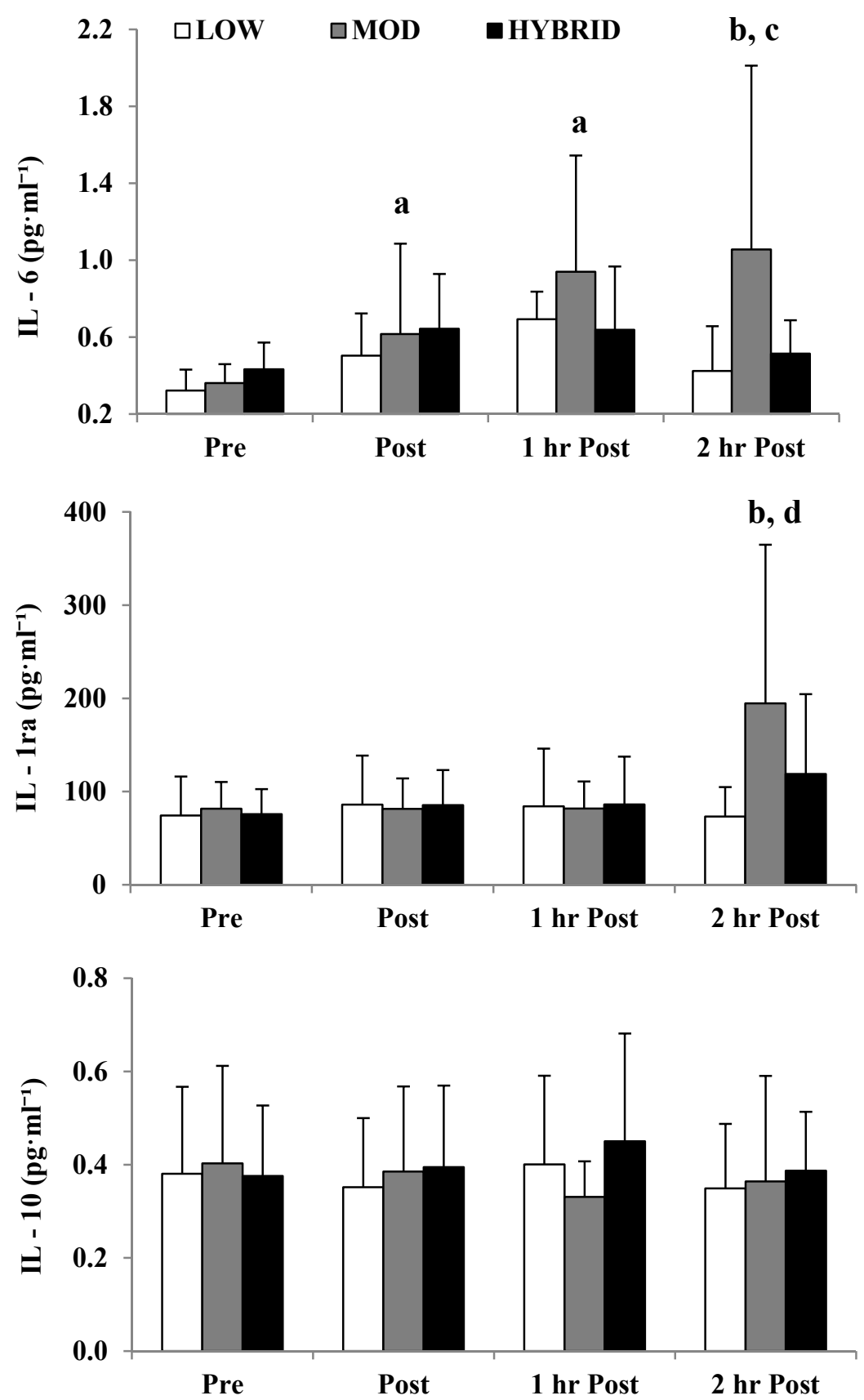


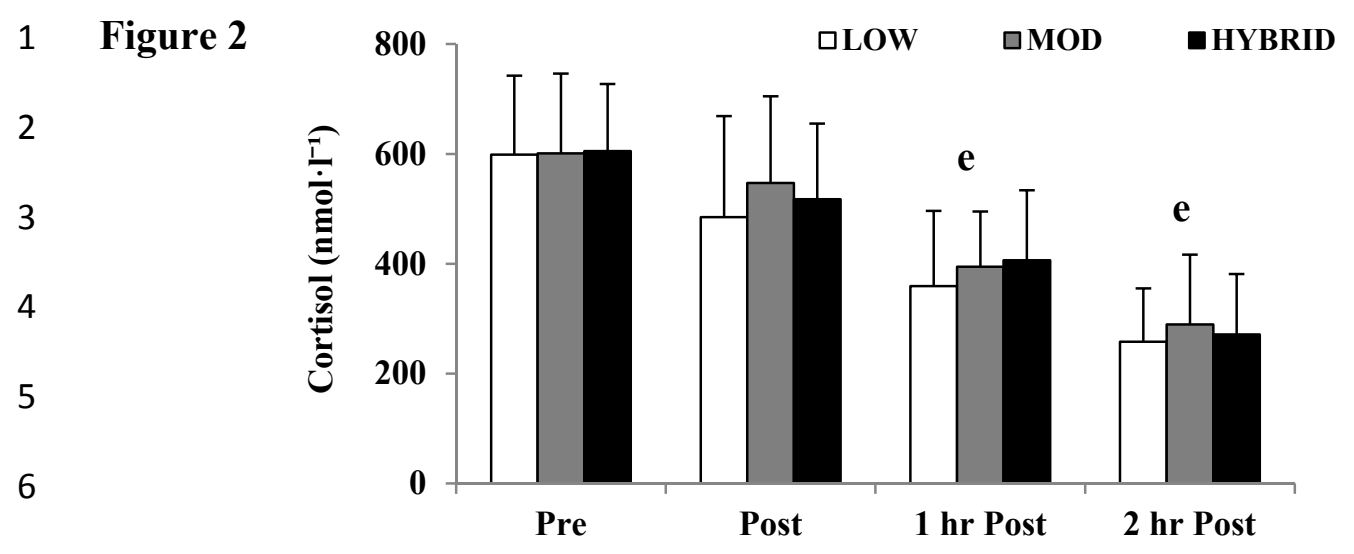

7

8

9

10

11

12

13

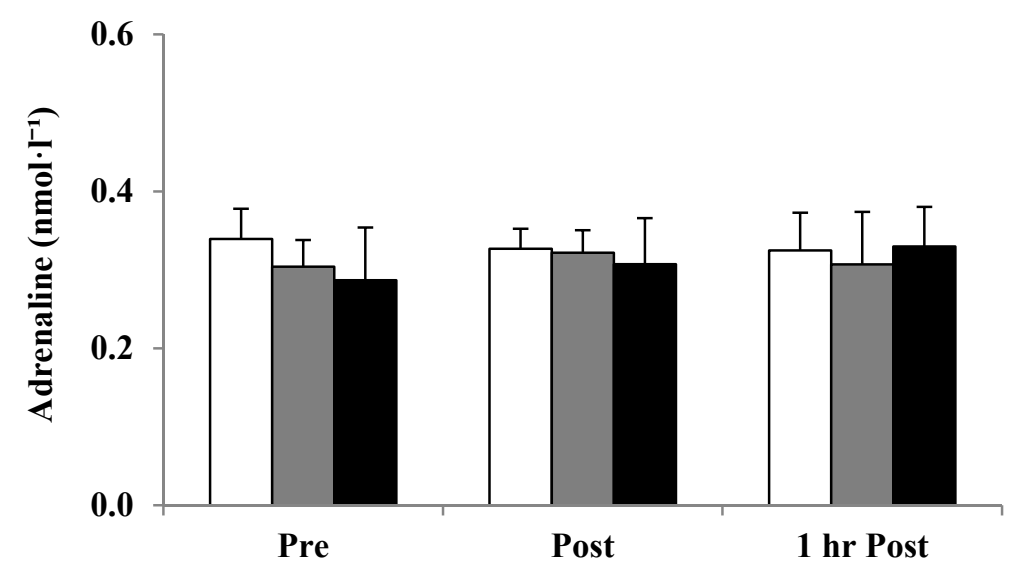

14 